\title{
COOPERAÇÃO UNIVERSIDADE - INDÚSTRIA NO BRASIL: SUAS \\ CARACTERÍSTICAS E DESAFIOS, A PARTIR DA PINTEC (2000-2017)
}

\author{
Pedro Faria \\ Graduando em Ciências Econômicas - Universidade Federal de Ouro Preto - UFOP \\ E-mail:pedropark99@gmail.com
}

\section{RESUMO}

As universidades e instituições de pesquisa são parte importante do sistema nacional de inovação, pois dão suporte às firmas na construção de suas capacidades tecnológicas. Neste artigo, busca-se mostrar a evolução recente das interações entre essas instituições e a indústria no Brasil, através dos dados da Pesquisa Industrial de Inovação Tecnológica (PINTEC). Os dados mostram que o cenário enunciado pela literatura se perpetua onde há uma participação muito baixa dessas instituições no desenvolvimento tecnológico recente do país (menos de $3 \%$ das firmas inovadoras responderam que colaboraram com universidades). Por isso, discute-se fatores que limitam essa cooperação, como as políticas macroeconômicas, que têm afetado negativamente o desenvolvimento tecnológico e industrial do país; a falta de diversidade e uma visão a longo prazo nas políticas de Ciência, Tecnologia e Inovação (CT\&l) atuais; a alocação de profissionais pós-graduados na economia; a exclusão de grande parte da população da educação superior; e além do mais, propõe-se algumas soluções.

Palavras-chave: Cooperação universidade-indústria; Economia da ciência e tecnologia; Pesquisadores pós-graduados; Divisão do aprendizado

\section{ABSTRACT}

Universities and research institutions are important parts of the national innovation system, as they support companies in building their technological competences. This article shows the recent 
evolution of interactions between these institutions and the industry in Brazil, based on the data from Industrial Research on Technological Innovation (PINTEC). The data indicates that the scenario presented in the literature is perpetuated where there is a considerably low participation of these institutions in the recent technological development of the country (less than $3 \%$ of innovative companies collaborate with universities). Thus, the article discusses factors that limit this interaction and proposes some solutions. Among these factors there are the macroeconomic policies, which have negatively affected the technological and industrial development of the country; the lack of diversity and a long-term view in current Science, Technology and Innovation (CT\&I) policies; the allocation of postgraduate professionals in the economy; and the exclusion of a large part of the population from higher education.

Keywords: University-industry cooperation; Economics of science and technology; Graduate researchers; Learning divide.

\section{INTRODUÇÃO}

No contexto atual de rápida transformação, o conhecimento tem sido tratado como o recurso mais valioso, e o aprendizado como o processo mais importante que ocorre na economia (LUNDVALL, 2010). É nesse contexto que as universidades e a ciência têm ganhado cada vez mais importância dentro do sistema de inovação de um país (GARCIA; RAPINI; CÁRIO, 2018), pois têm como objetivo produzir novos conhecimentos que possam orientar as ações dos agentes nas mais diversas circunstâncias, incluindo os processos e as atividades inovativas que ocorrem nas firmas. A importância dessas instituições no suporte tecnológico às empresas em seu processo inovativo motivou o surgimento de teorias de inovação modernas como a hélice tripla. Dada essa importância, este artigo mostra e discute a evolução recente da cooperação entre as universidades e a indústria no Brasil, através dos dados da PINTEC (2000-2017).

Rapini (2018) argumenta que a dificuldade do país em transformar conhecimentos acadêmicos em novos negócios ocorre por uma "quebra" entre duas áreas interligadas do aprendizado na economia, no sentido colocado por Arocena e Sutz (2010). Busca-se argumentar, de forma complementar à Rapini (2018), que, para além de suas proposições, a solução desses sintomas a longo prazo deve também incluir: 1) o prosseguimento na expansão do acesso ao ensino superior; 2) a diversificação das políticas de CT\&I (Ciência, Tecnologia e 
Inovação), em especial a inclusão de mais políticas pelo lado da demanda; 3) o incentivo ao investimento produtivo no país.

O artigo segue a seguinte estrutura: a seção 2 revê a literatura recente sobre cooperação na inovação; a seção 3 discute como foi estruturada a base da PINTEC; a seção 4 destaca as principais características da cooperação entre universidades e empresas no Brasil e utiliza os dados da PINTEC para discutir a sua evolução recente no país, além de apresentar os principais desafios que limitam essa cooperação apontados pela literatura; a seção 5 destaca um dos principais desafios da ciência brasileira, que é o desigual acesso à educação no país, e discute os sinais de piora no emprego de pesquisadores pós-graduados em P\&D (Pesquisa e Desenvolvimento) na indústria; a seção 6 discute sobre a forte queda nos investimentos produtivos no país, incluindo os incentivos à pesquisa básica, e a resultante queda nos esforços inovativos das firmas; a seção 7 conclui o artigo ao resumir os principais pontos abordados.

\section{INOVAÇÃO E COOPERAÇÃO}

Como foi destacado por Carlota Perez, a inovação é usualmente um processo coletivo, no qual cada vez mais agentes estão envolvidos, como fornecedores, distribuidores, entre outros, incluindo os próprios consumidores (PEREZ, 2010, p. 188). Logo, as firmas vêm dependendo cada vez menos do que pode ser produzido dentro delas para inovarem, ao se aproveitarem de ideias que podem ser encontradas fora delas. Um reflexo desse processo é a importância crescente da cooperação entre universidades e a indústria.

A importância da ciência para a atividade econômica foi reconhecida desde cedo por Adam Smith no primeiro capítulo de The Wealth of Nations, ao verificar que os avanços tecnológicos eram realizados não apenas na produção, mas também por fornecedores de bens de capital e por "philosophers and men of speculation", nome dado aos cientistas da época (PAVITT, 1991, p. 110). Segundo Garcia, Rapini e Cário (2018, p. 26), em um contexto no qual a complexidade dos produtos e processos produtivos é crescente, as empresas são obrigadas a procurar por novas fontes de conhecimento, e é nesta condição que as universidades e a pesquisa acadêmica têm ganhado um papel cada vez mais importante na transferência de novos conhecimentos para as empresas.

Na perspectiva da firma, a cooperação com essas instituições representa um grande incentivo à inovação, dado que as universidades e os institutos de pesquisa oferecem recursos e capacidades que podem ser importantes complementos para a empresa (LANGLOIS, 2009). 
Faria

Exemplos desses recursos são a oferta de laboratórios equipados, de pesquisadores altamente qualificados e a realização de experimentos e testes complexos. Além disso, a cooperação leva a um processo de aprendizado, que ocorre em ambas as partes (ALBUQUERQUE et al., 2015), e é uma forma viável de a firma dividir parte dos altos riscos com outro agente (SILVA; FURTADO; VONORTAS, 2018).

Para mais, as universidades são grandes produtoras de pesquisas básicas e aplicadas, que podem servir como apoio para inovações que ocorrem na indústria (CASSIOLATO et al., 2018). Um grande exemplo desse ponto foi dado por Mariana Mazzucato, ao elucidar que grande parte das tecnologias utilizadas no desenvolvimento do primeiro iPhone não foram desenvolvidas pela Apple. O argumento da autora é que essa inovação foi resultado de várias pesquisas e projetos financiados pelo dinheiro do governo americano e que se desenvolveram em diversas instituições de pesquisa e universidades públicas. Logo, a engenhosidade da Apple foi de identificar novas tecnologias com grande potencial, que estavam emergindo de diferentes pesquisas básicas e aplicadas, feitas em universidades americanas, e de utilizar as suas capacidades de engenharia para integrar essas tecnologias em um produto de grande sucesso comercial (MAZZUCATO, 2014).

Em suma, a crescente velocidade e a complexidade com que as mudanças ocorrem e a necessidade de as firmas acompanharem essas mudanças para se manterem competitivas pressionam cada vez mais empresas a buscarem por novas fontes de conhecimento (HORVAT; DREHER; SOM, 2019). Uma dessas fontes externas que tem ganhado cada vez mais importância são as universidades e os institutos de pesquisa (BRITTO et al., 2013; ALBUQUERQUE et al., 2015).

\section{BASE DE DADOS}

Neste artigo utiliza-se a Pesquisa de Inovação (PINTEC), classificada por atividades econômicas (CNAE - Classificação Nacional de Atividades Econômicas), que é realizada a cada 3 anos pelo Instituto Brasileiro de Geografia e Estatística (IBGE). Mais especificamente, serão consideradas todas as 7 edições publicadas entre 2000 e 2017.

Ao longo dos anos, a PINTEC sofreu modificações sobre a estrutura setorial utilizada. Exemplos dessa mudança são a inclusão dos setores de "Serviços" a partir da edição de 2005, e de "Eletricidade e Gás" a partir da edição de 2011 . Essas alterações ocorreram de maneira mais drástica na edição de 2008 da pesquisa, com a publicação e mudança da CNAE 1.0 para 
a CNAE 2.0'. Por esse motivo, o cruzamento de dados de algumas atividades econômicas entre as sete edições da PINTEC é tênue, visto que algumas classes da CNAE 1.0 foram fundidas na CNAE 2.0 e, portanto, ficaram inseparáveis.

Por isso, muitos setores não puderam ser cruzados ao longo das edições. Em outras palavras, não foi possível montar uma "série temporal" de vários setores para cada variável. Contudo, os setores de todas as edições da pesquisa foram considerados, mesmo aqueles setores que se encontravam em apenas uma das edições. Como resultado, obteve-se 292 observações para 66 setores diferentes ao longo das 7 edições. Em mais detalhes, foram considerados 30 setores em 2000, 29 em 2003, 36 em 2005, 38 em 2008 e 53 em 2011, 2014 e 2017.

\section{COOPERAÇÃO ENTRE UNIVERSIDADES E INDÚSTRIA (U-I) NO BRASIL}

\subsection{EVOLUÇÃO RECENTE SEGUNDO A LITERATURA E OS DADOS DA PINTEC}

A mudança tecnológica que ocorre nos países centrais constantemente altera e remodela os desafios que os países periféricos enfrentam para um processo de catch-up. Por isso, a habilidade desses países de acessar o conhecimento e a tecnologia dos países centrais é não só um importante fator que divide a periferia do centro, mas também um meio de superar essa divisão. Com isso, as universidades e as instituições públicas de pesquisa ganham novamente grande relevância no contexto periférico brasileiro, pois são importantes canais de acesso aos fluxos internacionais da ciência e da tecnologia (ALBUQUERQUE et al., 2015).

No caso do Brasil, a literatura o caracteriza como um país em que há poucos pontos de cooperação de sucesso, formados há um longo tempo e que vêm se perpetuando (RAPINI et al., 2009; ALBUQUERQUE et al., 2015; SILVA; FURTADO; VONORTAS, 2018; CASSIOLATO; LASTRES, 2019). Diferentemente dos países centrais, como mostram Rapini (2007), Rapini et al. (2009) e Suzigan et al. (2009), no Brasil as áreas da indústria de baixa e média tecnologia (especialmente aquelas ligadas às ciências agrárias e à engenharia) têm grande importância nos casos de cooperação U-I existentes.

A construção das relações entre universidades e indústria é um processo dinâmico, que se intensifica na medida em que problemas mais difíceis e complexos são apresentados pela

\footnotetext{
1 Classificação Nacional de Atividades Econômicas. Resolução CONCLA $01 / 2006$ publicada no Diário Oficial em 05/09/2006. Site para mais detalhes: <https://cnae.ibge.govol.br/classificacoes/por-tema/atividadeseconomicas/classificacao-nacional-de-atividades-economicas $>$.
} 
sociedade (ALBUQUERQUE et al., 2015), ou ainda, na medida em que o nível de sofisticação da indústria e dos mercados do país, aumenta (SILVA; FURTADO; VONORTAS, 2018). Por isso a heterogeneidade da base tecnológica e o processo histórico do país são apontados como os principais motivos pelos quais a cooperação entre U-I não é comum no Brasil (SILVA; FURTADO; VONORTAS, 2018). A formação histórica do Brasil mostra que não só as suas instituições de pesquisa e de suporte tecnológico demoraram a ser criadas, mas que o processo de industrialização também demorou a se formar. Após a adoção da política de substituição de importações, se formou no Brasil, uma base industrial muito diversa e com diferentes níveis de participação econômica e tecnológica, na qual setores de alta complexidade convivem com setores atrasados (SILVA; FURTADO; VONORTAS, 2018). Além disso, como é bem descrito por Cassiolato e Lastres (2014), as políticas de CT\&I foram bem instáveis e quase inexistentes durante a segunda metade do século $X X$ e só foram retomadas com efeito prático no país a partir de 1999, com uma visão ainda bastante restrita ao modelo linear de inovação.

Em geral, as áreas mais maduras da economia brasileira e com maior presença na pauta exportadora do país (agropecuária, tecnologia de alimentos, mineração, extração de petróleo, metalurgia, papel e equipamentos elétricos) refletem justamente os pontos de cooperação de sucesso na indústria. Esse é um ponto chave que diferencia o Brasil dos países centrais, no que tange à cooperação U-I. À vista disso, como Freitas et al. (2013) destaca, indústrias maduras e estabelecidas enfrentam uma incerteza tecnológica menor e, com isso, a competição começa a se basear cada vez mais na redução de custos e em pequenas inovações em produto, diferentemente das indústrias emergentes, que são caracterizadas por grande competição em tecnologia, em desenvolvimento de novos produtos e por grande turbulência no mercado (FREITAS, 2013)

Pode-se ver reflexos dessa realidade sobre os motivos pelos quais as firmas procuram pelas universidades, sendo os principais: treinamento de pessoal, avaliações técnicas e estudos de viabilidade e contratação de P\&D complementar às atividades da empresa (RAPINI, 2007; SUZIGAN et al., 2009; FREITAS et al., 2013). Indústrias maduras tendem a depender de conhecimentos codificados (ao invés de tácitos) para inovarem (FREITAS et al., 2013), e o treinamento de pessoal e avaliações técnicas são formas de transferir esse tipo de conhecimento. Sendo que essas duas atividades dizem respeito a uma demanda por insumos acadêmicos pouco sofisticados (RAPINI, 2007). A contratação de P\&D também mostra uma baixa capacidade tecnológica das firmas brasileiras, ao terem de complementar suas capacidades contratando P\&D externo das universidades (RAPINI et al., 2009). 
Os dados da PINTEC apontam que essas interações avançaram muito pouco no Brasil. Na tabela 1, pode ser visto a participação de diversas instituições como fontes de informação (de alta importância) no total de respostas das empresas que implementaram inovações. As universidades permaneceram praticamente no mesmo lugar durante todo o período (com 2,37\% das respostas), estando na penúltima colocação, e os institutos de pesquisa (com 2,68\% das respostas) logo atrás, com um aumento muito leve em sua participação.

Tabela 1: Proporção do total de respostas (de alta importância) das empresas que implementaram inovações em cada fonte de informação.

\begin{tabular}{|lcccccccc}
\hline \multicolumn{1}{c}{ Fonte de informação } & $\mathbf{2 0 0 0}$ & $\mathbf{2 0 0 3}$ & $\mathbf{2 0 0 5}$ & $\mathbf{2 0 0 8}$ & $\mathbf{2 0 1 1}$ & $\mathbf{2 0 1 4}$ & $\mathbf{2 0 1 7}$ \\
\hline Redes de informação (\%) & 6,38 & 11,44 & 13,51 & 16,17 & 16,92 & 18,56 & 18,99 \\
\hline Clientes ou consumidores (\%) & 15,12 & 14,47 & 15,48 & 15,19 & 14,21 & 14,38 & 15,01 \\
\hline Fornecedores (\%) & 15,61 & 14,33 & 14,66 & 12,89 & 14,01 & 12,96 & 12,74 \\
\hline Outras áreas da empresa (\%) & 17,86 & 17,68 & 15,15 & 12,78 & 11,29 & 10,12 & 10,22 \\
\hline Feiras e exposições (\%) & 14,32 & 14,64 & 13,36 & 10,71 & 10,69 & 10,47 & 8,66 \\
\hline Concorrentes (\%) & 8,99 & 8,46 & 8,51 & 7,70 & 7,91 & 8,41 & 7,60 \\
\hline Empresa de consultoria (\%) & 1,89 & 2,24 & 2,28 & 3,50 & 3,36 & 4,25 & 4,68 \\
\hline Instituições de teste (\%) & 2,65 & 2,44 & 2,79 & 3,61 & 3,84 & 4,08 & 4,47 \\
\hline Conferências, encontros e publicações (\%) & 6,17 & 6,25 & 5,53 & 5,65 & 4,92 & 3,89 & 4,09 \\
\hline P\&D interno(\%) & 4,17 & 2,36 & 2,84 & 2,55 & 3,49 & 3,20 & 3,81 \\
\hline Centro de capacitação profissional (\%) & 2,58 & 2,34 & 2,42 & 3,39 & 4,06 & 3,75 & 3,34 \\
\hline Instituto de pesquisa (\%) & 0,00 & 0,00 & 0,00 & 1,75 & 2,18 & 2,42 & 2,68 \\
\hline Universidades (\%) & 2,09 & 1,82 & 2,28 & 2,15 & 2,32 & 2,30 & 2,37 \\
\hline Outra empresa do grupo (\%) & 2,17 & 1,54 & 1,18 & 1,97 & 0,80 & 1,21 & 1,34 \\
\hline
\end{tabular}

Fonte: Base de dados da PINTEC - IBGE.

Na tabela 2, tem-se a proporção de empresas com relações de cooperação com cada agente (e que classificaram essa cooperação como de alta importância) em relação ao total de empresas que inovaram em produto ou em processo no ano. Na referida tabela, vê-se um cenário parecido, no qual essas instituições ganharam um espaço muito pequeno, chegando a $2,65 \%$ em 2017. Portanto, os dados indicam alguma melhora, porém insuficiente para mudar o panorama encontrado na literatura, no qual menos de $3 \%$ das firmas inovadoras no Brasil, cooperam com universidades. Tal número para a maioria dos países da Organização para Cooperação e Desenvolvimento Econômico (OECD), chega a 10\% (CASSIOLATO; LASTRES, 2019). 
Tabela 2: Proporção do total de firmas inovadoras com relações de cooperação com cada agente.

\begin{tabular}{lccccccc}
\hline \multicolumn{1}{c}{ Agente com o qual cooperou } & $\mathbf{2 0 0 0}$ & $\mathbf{2 0 0 3}$ & $\mathbf{2 0 0 5}$ & $\mathbf{2 0 0 8}$ & $\mathbf{2 0 1 1}$ & $\mathbf{2 0 1 4}$ & $\mathbf{2 0 1 7}$ \\
\hline Clientes ou consumidores (\%) & 3,77 & 1,26 & 3,98 & 3,67 & 6,89 & 8,26 & 8,83 \\
Fornecedores (\%) & 4,26 & 1,26 & 3,75 & 5,42 & 8,38 & 8,29 & 6,83 \\
Concorrentes (\%) & 0,74 & 0,14 & 0,79 & 1,16 & 2,10 & 1,75 & 1,38 \\
Outra empresa do grupo (\%) & 1,87 & 0,57 & 0,98 & 1,24 & 0,94 & 1,93 & 1,57 \\
Empresa de consultoria (\%) & 0,71 & 0,22 & 1,30 & 2,04 & 2,87 & 2,51 & 2,65 \\
Universidades e institutos de pesquisa (\%) & 1,50 & 0,62 & 1,67 & 2,04 & 3,02 & 2,22 & 2,65 \\
Centros de capacitação profissional (\%) & 0,58 & 0,30 & 0,85 & 1,76 & 2,77 & 1,75 & 1,42 \\
\hline
\end{tabular}

Fonte: Base de dados da PINTEC - IBGE.

Ainda na tabela 1, é possível observar o crescimento expressivo de redes de informação (internet), sendo desde 2008 a fonte de informação mais importante para as empresas inovarem. Ao mesmo tempo, constata-se uma presença forte em ambas as tabelas acima, de clientes e consumidores. A literatura aponta que os consumidores são a principal fonte de informação das empresas brasileiras na concepção de novos projetos (RAPINI et al., 2009). Tal padrão também é encontrado em estudos de países desenvolvidos, como os feitos por Von Hippel (1988) ou Cohen et al. (2002). Em ambos os estudos, os pesquisadores concluíram que, em quase todas as indústrias norte-americanas analisadas, os compradores e os próprios processos de produção eram as principais fontes para o início de novos projetos de P\&D.

Por meio da evolução apresentada pelos dados da PINTEC, é possível compreender que essas relações vêm se intensificando no Brasil, onde as firmas estão cada vez mais próximas de seus clientes, como acontece com as redes sociais. Além dessas considerações, capta-se uma queda relativa de fornecedores em ambas as tabelas. Essa queda pode ser explicada tanto pela perda recente do suporte público na compra de máquinas e equipamentos (veja a seção 6), quanto pela queda no investimento produtivo da indústria.

Em comparação a 2014, tanto o número total de empresas que implementaram inovações quanto o número total de empresas que cooperaram com outros agentes caíram em 2017, indo de 47.693 para 39.329 , bem como de 7.300 para 6.120 , respectivamente. Com isso, a porcentagem de empresas que implementaram inovações e cooperaram com algum agente permaneceu praticamente constante em 15\%, apesar da queda em termos absolutos do número de empresas que cooperaram. Em 2017, as universidades e os institutos de pesquisas foram os únicos agentes que obtiveram um aumento no número bruto de empresas parceiras (todos os outros agentes obtiveram quedas). Por esse motivo, as universidades e institutos de 
pesquisas chegaram a aumentar sua participação no total de empresas que cooperaram no ano de 2017. Entretanto, esse aumento absoluto foi apenas de 13 empresas (em comparação a 2014 ) e, como é possível observar nas tabelas 1 e 2, esse resultado não mostra uma mudança significativa na rede de relações das empresas.

\subsection{DESAFIOS QUE PERSISTEM}

Os dados da PINTEC expõem uma fraca evolução das interações entre a universidade e a indústria nos últimos anos. Segundo Rapini (2018), o principal fator que limita a transformação de conhecimento científico em novos negócios no Brasil, é uma "fragmentação do processo de aprendizado", no sentido dado por Arocena e Sutz (2010). Essa quebra ocorre em dois lados que estão interligados, sendo de um lado a oferta (learning by studing) e de outro a demanda (learning by solving problems).

Em primeiro lugar, há uma desconexão entre as áreas da ciência que geram maior oferta, e as áreas mais essenciais ao desenvolvimento tecnológico do país. Ou seja, existe uma má alocação dos estudantes ao longo das áreas da ciência. Há uma grande tendência para as Humanidades e Ciências Sociais no total de concluintes de graduações, onde áreas mais requisitadas para os desafios técnicos das empresas, como engenharias, Ciências Exatas e Ciências da Computação, responderam juntas por apenas $14,5 \%$ dos concluintes no ano de 2015 (RAPINI, 2018). Consequentemente, esse padrão reflete em uma menor presença dessas áreas sobre o total de pesquisadores formados e de artigos publicados.

Em segundo lugar, há uma baixa demanda das empresas por conhecimentos de alta complexidade. Apesar da maior oferta nos anos recentes de pesquisadores e profissionais pósgraduados no país, esses não recebem propostas das empresas, correspondentes aos conhecimentos que possuem (RAPINI, 2018). Como consequência, os profissionais procuram por ofícios em outras áreas (ao invés de estarem empregados na produção), concentrando-se especialmente na administração pública (MAZZUCATO; PENNA, 2016). Ademais, grande parte dos profissionais com diplomas nas áreas de engenharia, acabam migrando para outras áreas em que há melhor remuneração, como as áreas de gestão, por exemplo (RAPINI; CHIARINI; BITTENCOURT, 2017).

Portanto, existe uma forte concentração da oferta de profissionais altamente qualificados em áreas, que são importantes, mas que não colaboram para o desenvolvimento das capacidades tecnológicas das firmas (uma desconexão do learning by studing com as 
necessidades das empresas). Para mais, há uma demanda muito fraca por esses profissionais (o que resulta em poucas oportunidades de learning by solving problems), que acabam migrando para outras áreas ou outras localidades em busca dessa demanda. Dessa forma, a queda na procura das firmas por atividades inovativas, levou a uma preocupante queda no emprego de pesquisadores pós-graduados na produção, o que reforçou os sintomas enunciados pela literatura em questão. De forma complementar à análise de Rapini (2018), conclui-se que as soluções para esses problemas também devem envolver: 1) a expansão do acesso ao ensino superior; 2) a diversificação das políticas de CT\&l; e 3) a retomada do nível de investimento produtivo na economia.

\section{CAPITAL hUMANO E CENÁRIO DA EDUCAÇÃo NO PAÍS}

\subsection{EDUCAÇÃO BÁSICA E O ACESSO RESTRITO AO ENSINO SUPERIOR}

Rapini (2018) sugere uma maior conexão entre os planos educacionais do Ministério da Educação (MEC) com as áreas priorizadas pelo Ministério da Ciência, Tecnologia e Inovações (MCTI), para que haja uma distribuição mais homogênea dos estudantes nas áreas científicas. Entretanto, se comparado a outros países, o acesso à educação superior continua muito restrito no Brasil. Logo, uma redistribuição é essencial no curto prazo, mas a longo prazo (na medida em que a complexidade dos mercados e da demanda das firmas aumentarem), ressalta-se que essa estratégia sozinha pode gerar uma oferta ainda insuficiente para as empresas.

Em muitas ocasiões, o treinamento e as experiências adquiridas no trabalho (learning by doing e learning by solving problems) podem se constituir como meios mais importantes de aprendizado. Por outro lado, a educação formal é muitas vezes uma condição necessária para a aquisição de habilidades industriais, uma vez que, à medida que as tecnologias mais complexas são adotadas, a exigência por habilidades mais avançadas e especializadas emergem, tanto por parte dos trabalhadores quanto por parte dos administradores (LALL, 1992). Logo, a educação formal constitui-se como uma das formas mais importantes de se adquirir conhecimento e formar habilidades.

Portanto, a educação não é equivalente ao estoque de aptidões, mas proporciona a base para a ocorrência do aprendizado a níveis tecnológicos mais altos, e, por isso a educação fornece uma noção do aprendizado potencial de um país (LALL, 2005). No Brasil, ela vem melhorando em diversas frentes, como o acesso em todos os níveis educacionais e na taxa de 
analfabetismo ${ }^{2}$, mas ainda sofre de diversos problemas gerados pela desigualdade social do país, sendo tão profundos que encontram-se enraizados não apenas a níveis de renda, mas regionais, raciais e de gênero (CASTRO, 2009).

É possível analisar reflexos destes problemas na tabela 3. Percebe-se que o Brasil, no nível do ensino médio e técnico (ISCED 3 e 4), possui uma taxa de matrícula relativamente alta em comparação com os outros países. Em contrapartida, o país obteve um desempenho muito abaixo no PISA, em 2018, em todas as três áreas do teste, o que reflete a qualidade da educação básica no país. De acordo com os relatórios do PISA ${ }^{3}$, as notas obtidas pelo Brasil não mudaram significativamente em comparação aos testes passados, visto que apenas $2 \%$ dos estudantes performaram nos níveis mais altos (níveis 5 e 6) em pelo menos uma área da prova (média dos países da OECD: 16\%).

Tabela 3: Indicadores de qualidade e acesso à educação formal de países selecionados.

\begin{tabular}{|c|c|c|c|c|c|c|}
\hline \multirow[b]{2}{*}{ País } & \multicolumn{2}{|c|}{ Matrículas (\%) } & \multirow[b]{2}{*}{$\begin{array}{l}\text { Média de anos } \\
\text { de escolaridade }\end{array}$} & \multirow{2}{*}{$\begin{array}{l}\text { PISA - Ciências } \\
\text { Colocação (Nota) }\end{array}$} & \multirow{2}{*}{$\begin{array}{l}\text { PISA - Matemática } \\
\text { Colocação (Nota) }\end{array}$} & \multirow{2}{*}{$\begin{array}{c}\text { PISA - Leitura } \\
\text { Colocação (Nota) }\end{array}$} \\
\hline & $\begin{array}{c}\text { ISCED níveis } \\
3 \text { e } 4\end{array}$ & $\begin{array}{c}\text { ISCED níveis } 5 \\
\text { a } 8\end{array}$ & & & & \\
\hline Brasil & 34,09 & 17,21 & 7,80 & $66^{\circ}(404)$ & $70^{\circ}(384)$ & $57^{\circ}(413)$ \\
\hline México & 21,17 & 17,98 & 8,60 & $57^{\circ}(419)$ & $61^{\circ}(409)$ & $53^{\circ}(420)$ \\
\hline Canadá & 23,27 & 57,89 & 13,30 & $8^{\circ}(518)$ & $12^{\circ}(512)$ & $6^{\circ}(520)$ \\
\hline Alemanha & 45,43 & 29,07 & 14,10 & $16^{\circ}(503)$ & $20^{\circ}(500)$ & $20^{\circ}(498)$ \\
\hline Japão & 48,07 & 51,93 & 12,80 & $5^{\circ}(529)$ & $6^{\circ}(527)$ & $15^{\circ}(504)$ \\
\hline Coréia do Sul & 39,18 & 49,01 & 12,10 & $7^{\circ}(519)$ & $7^{\circ}(526)$ & $9^{\circ}(514)$ \\
\hline Reino Unido & 20,95 & 45,78 & 12,90 & $14^{\circ}(505)$ & $18^{\circ}(502)$ & $14^{\circ}(504)$ \\
\hline Estados Unidos & 43,39 & 47,43 & 13,40 & $18^{\circ}(502)$ & $37^{\circ}(478)$ & $13^{\circ}(505)$ \\
\hline
\end{tabular}

Fonte: Porcentagem da população, entre 25 e 64 anos, matriculada (dados de 2018), OECD Statistics; Média de anos de escolaridade (dados de 2017), Our World in Data; PISA 2018 Results (Volume I) OECD 2019. Elaboração própria do autor.

Segundo os relatórios da Síntese de Indicadores Sociais (SIS), em 2018 o ensino fundamental (ISCED níveis 1 e 2) no Brasil permaneceu com as taxas de frequência escolar praticamente universais, e desde 2003 houve uma expansão significativa no acesso à educação infantil, subindo a taxa de frequência escolar de 13,4\% em 2003 (IBGE, 2014) para 34,2\% em 2018 (IBGE, 2019). Entretanto, como foi exposto acima, mais do que o amplo acesso à

\footnotetext{
${ }^{2}$ Apesar de que a taxa de analfabetismo continua a ser um problema, (Índice de 2018: 6,77\%, Fonte: World Bank).

3 Programme for International Student Assessment - PISA/OECD.
} 
educação básica, é necessário também que ele venha acompanhado da qualidade de ensino, para gerar bons resultados.

Segundo Bruns, Evans e Luque (2012), desde 1993 quase todas as crianças no Brasil iniciavam seus anos escolares. Por isso, o grande avanço na educação brasileira nos últimos anos não tem sido o acesso quase universal à educação básica, mas, sim, a maior permanência dessas crianças na escola. Em 2009 (comparando-se com 1993), a porcentagem de crianças que completavam o ensino básico e entravam no ensino médio subiu de $42 \%$ para $71 \%$. Já a porcentagem de crianças que completaram o ensino médio subiu de $28 \%$ para $55 \%$ (BRUNS; EVANS; LUQUE, 2012, p. 25). Mesmo com a melhora, esses números ainda mostram um grande nível de evasão. Como resultado, muitas pessoas não completam o ensino médio e não podem sequer se candidatar a uma vaga no ensino superior (tabela 3, ISCED níveis 5 a 8 ). Dito de outra forma, os números apresentados por Bruns, Evans e Luque (2012, Figura 10), assim como os números expostos na tabela 3 (ISCED níveis 5 a 8 ), mostram uma baixa oferta de mão de obra especializada, em geral, no país. Dessa forma, poucas pessoas podem contribuir com as ciências e com o desenvolvimento tecnológico brasileiro.

Os documentos da SIS também mostram que no caso do ensino médio (ISCED nível 3) há sérios problemas a serem enfrentados. Em 2018, a taxa de frequência escolar dos jovens de 15 a 17 anos (faixa etária correspondente ao ensino médio) estava em 88,2\%. Portanto, no mesmo ano, cerca de $11,8 \%$ dos jovens entre 15 e 17 anos não frequentavam a escola. Após cálculos de adequação, descobriu-se que $23,1 \%$ dessa mesma faixa etária estavam dentro da escola, porém fora da etapa adequada. Em outras palavras, os alunos que já deveriam estar no ensino médio ainda permaneciam no ensino fundamental (IBGE, 2019).

O atraso escolar se faz um grande empecilho, uma vez que os alunos podem se sentir desmotivados e as chances de abandonarem o ensino aumentam. À vista disso, ○ Brasil possui um percentual médio de adultos entre 25 e 64 anos que não concluíram o ensino médio no ano de 2017, em torno de 27 pontos percentuais acima da média dos países da OECD (IBGE, 2019). A evasão escolar estimada no ensino médio em 2015 chegou a 12,9\% e a 12,7\% nos dois primeiros anos dessa fase escolar (INEP, 2017).

Além desses fatores, há várias evidências de que pressões fisiológicas e psicológicas durante os primeiros anos de infância podem afetar a performance do aprendizado ao longo da vida (ALDERMAN, 2011). O Brasil não enfrenta alguns estressores, como a exposição à Guerra Civil durante a infância, mas parte das crianças brasileiras são expostas a outros problemas que geram impactos graves no aprendizado e nos resultados educacionais. Como, 
por exemplo, a violência doméstica, o trabalho infantil, o uso de drogas, a exploração e o abuso sexual. Além desses, existem outros estressores que afetam a população em geral, como altas taxas de suicídio, de violência e de homicídios (REICHENHEIM et al., 2011, MORAES et al., 2017). Uma observação ao longo destes estudos foi a parte da população mais pobre como sendo a principal vítima desses diversos tipos de violências analisadas.

Em síntese, o ensino básico público (que atende grande parte da população) possui uma qualidade aquém do ideal, e as desigualdades sociais e a violência continuam a limitar o desenvolvimento educacional das crianças, e contribuem para a evasão escolar. Tais fatos implicam em uma média baixa de anos de escolaridade, e um baixo acesso à educação superior no país, tal como apresentado na tabela 3, mesmo após os esforços recentes (em especial nos governos do ex-presidente Lula) para a expansão do ensino superior no país (RAPINI; CHIARINI; BITTENCOURT, 2017). À vista disso, faz-se necessário no longo prazo não apenas políticas públicas que alterem os incentivos para os estudantes, de forma a moldar uma melhor distribuição nas áreas científicas, como proposto por Rapini (2018), mas também políticas de melhorias da educação básica que ampliem o acesso ao ensino superior e, consequentemente, a participação da população nos desafios tecnológicos do país.

\subsection{PESQUISADORES PÓS-GRADUADOS}

Há várias barreiras que dificultam a cooperação entre as universidades e a indústria. Uma delas está ligada às incertezas e aos problemas contratuais da relação. Como é impossível prever as implicações de uma provável quebra ou comercialização dos resultados das pesquisas científicas, é possível que uma das partes queira se aproveitar, em benefício próprio, de oportunidades que surjam dessa colaboração (BRUNEEL; D'ESTE; SALTER, 2010). Logo, os termos e a confiança que regem o contrato entre ambas as partes tornam-se fatores importantes e, por isso, novas adições à Lei de Inovação (10.973/2004) podem ter grandes efeitos sobre as relações entre firmas e instituições de suporte tecnológico.

A atuação de pesquisadores pós-graduados na produção também pode ser fundamental para superar parte dessas barreiras, pois esses pesquisadores são canais importantes de comunicação entre a firma e a universidade. Dito de outra forma, as conexões sociais (social network) que pesquisadores possuem com o meio científico podem oferecer oportunidades importantes para as empresas (MURRAY, 2004). Muitas das vezes em que a organização enfrenta um problema que é muito específico ou muito complexo, conhecer alguém 
que saiba resolver esse problema (know-who) é mais importante do que possuir o conhecimento para resolver o problema (know-how) em si (LUNDVALL, 2006).

Além disso, os pesquisadores pós-graduados carregam conhecimentos tácitos importantes sobre a fronteira científica de sua área, consequentemente, a sua presença pode envolver a transferência desses conhecimentos para a firma (MURRAY, 2004). Esses profissionais são treinados com o intuito de gerarem pesquisas e novos conhecimentos, por isso, podem ajudar a empresa a construir suas capacidades tecnológicas (CASSIOLATO et al., 2018).

No entanto, em um relatório sobre a situação dos profissionais com pós-graduação no Brasil, realizado em 2015, constatou-se uma alta concentração dos mestres (53\%) e doutores (71,9\%) empregados em 2014, no setor da administração pública (CGEE, 2015, Tabelas 6.02 e 6.04). Apenas $27,6 \%$ dos mestres e $11,4 \%$ dos doutores se encontravam empregados em entidades empresariais (privadas e estatais). Mazzucato e Penna (2016) e Cassiolato e Lastres (2019) reforçaram essa problemática no sistema de inovação brasileiro, ao pontuarem que esses profissionais poderiam contribuir de forma mais direta no desenvolvimento das capacidades tecnológicas das firmas, se tivessem uma maior presença nos setores produtivos da economia, estando, assim, diretamente ligados à produção.

Com o objetivo de captar a evolução desses profissionais, a figura 1 foi montada. As barras no gráfico, representam a média de pesquisadores empregados em P\&D (com ensino superior e com dedicação exclusiva) por empresa inovadora. Essa média foi calculada, apenas com os dados da PINTEC referentes aos setores da indústria de transformação (CNAE Divisão 10-33). Já as linhas no gráfico, apresentam o número total de formandos no ensino superior por 10 mil ou por 100 mil habitantes. Esses números foram calculados com base nos dados disponíveis na plataforma GeoCapes4, levando-se em conta, apenas as áreas de Engenharia, Ciências Agrárias e Ciências Exatas e da Terra.

Na figura 1, o recuo acentuado na média de pesquisadores empregados por empresa inovadora, mostra um efeito negativo sobre as capacidades tecnológicas das empresas. Para mais, essa queda ocorre ao mesmo tempo em que os índices de formação de profissionais com algum nível superior continuam a aumentar. Isso pode significar duas coisas: 1) o desemprego entre esses profissionais com ensino superior está aumentando; 2) há um agravamento da má alocação desses profissionais na economia, ou seja, os novos profissionais formados estão migrando cada vez mais para outros setores, ao invés dos setores produtivos da indústria.

${ }^{4}$ https://geocapes.capes.gov.br/geocapes/ 
Figura 1: Média anual de pesquisadores por empresa inovadora e número de concluintes de Engenharias, Ciências Agrárias e Ciências Exatas e da Terra no ensino superior, por nível de formação.

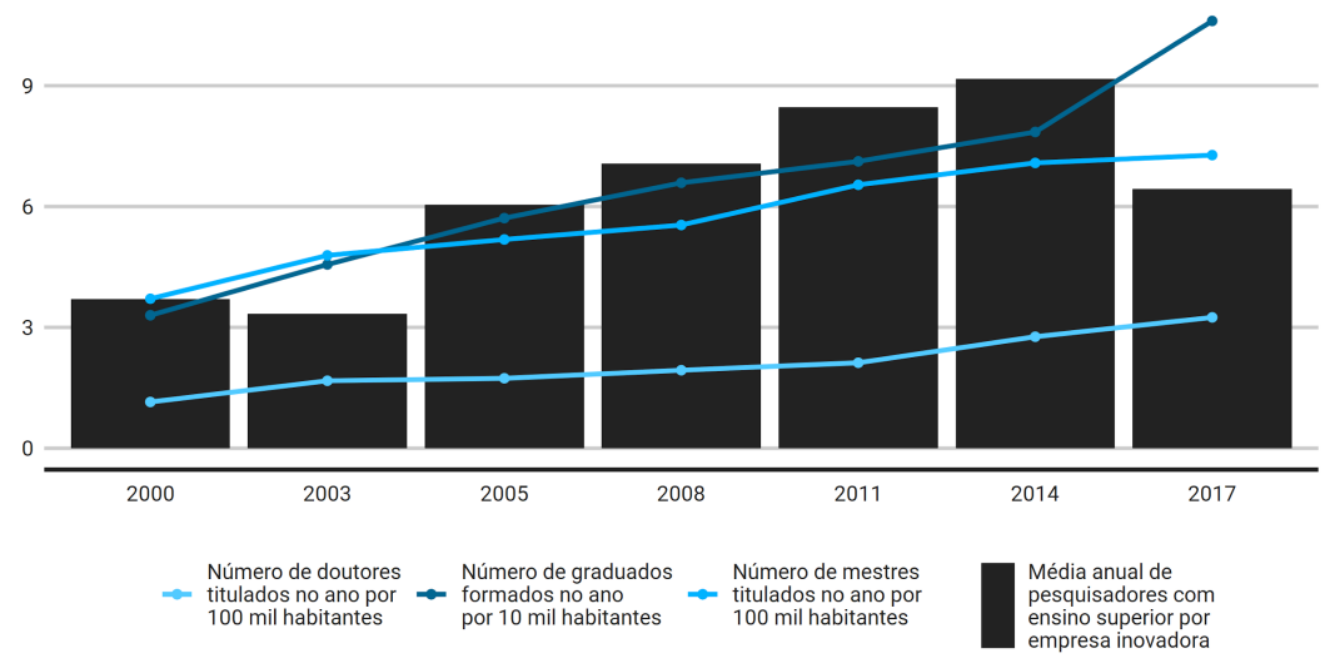

Fonte: Pesquisadores por empresa inovadora, PINTEC-IBGE; Concluintes de cursos presenciais de graduação, Censo do Ensino Superior - INEP/MEC; Mestres e Doutores titulados no ano, GeoCapes CAPES/MEC; População estimada - IBGE. Elaboração própria do autor.

Há alguma evidência empírica para o primeiro cenário, no qual a taxa de desemprego estimada dos profissionais com ensino superior, subiu de 5,06\% no primeiro trimestre de 2014 (IPEA, 2016) para 7,8\% no quarto trimestre de 2017 (IPEA, 2020). Indicadores como os construídos pelo Centro de Gestão e Estudos Estratégicos (CGEE, 2015) são necessários para confirmar o segundo cenário. Contudo, esse panorama é preocupante, e faz-se necessário descobrir se os indicadores, de fato, sustentam-se na perspectiva atual e quais são as suas intensidades.

Rapini (2018) e Mazzucato e Penna (2016), argumentam que a demanda das firmas por conhecimentos complexos estava baixa, e a figura 3 mostra que esse cenário se agravou. Essa queda no emprego de pesquisadores em atividades de $P \& D$, pode ser explicada, em grande parte, pela inversão do investimento no período. Como consequência deste declínio, as 
empresas têm focado na redução de custos e no lucro a curto prazo, não deixando espaço para investimentos a longo prazo como, por exemplo, as atividades inovativas.

As tabelas da PINTEC não possuem alguns dos setores importantes caracterizados por Rapini (2007) e Suzigan et al. (2009), especialmente aqueles diretamente ligados às Ciências Agrárias. Entretanto, essas tabelas possuem outros setores citados pelos autores e relacionados às áreas da metalurgia e da indústria química. Na tabela 4 , tem-se a variação do número de pesquisadores empregados em P\&D (com ensino superior), nos 14 setores que obtiveram na edição de 2014, as maiores proporções de empresas inovadoras que cooperaram com universidades, em relação ao total de empresas inovadoras.

Ainda na tabela 4, foi empregado a classificação setorial por intensidade tecnológica da OECD, mais especificamente, a sua correspondência com a revisão 2.1 da CNAE, proposta por Cavalcante (2014). Essa classificação da OECD foi construída com base em indicadores de intensidade tecnológica, sendo o principal deles, a proporção dos gastos em P\&D do setor em relação ao seu valor adicionado 5 .

Primeiro, observa-se uma queda acentuada do emprego de pesquisadores no setor de fabricação de automóveis. Esse gráfico indica que os setores de alta intensidade tecnológica (fabricação de automóveis, fabricação de resinas e elastômeros, fabricação de equipamentos de informática e periféricos e fabricação de outros produtos eletrônicos e ópticos) foram os mais afetados em relação ao emprego de pesquisadores, enquanto alguns setores de menor intensidade (fabricação de fumo, fabricação de celulose e fabricação de coque e biocombustíveis) chegaram a obter um pequeno aumento no número de pesquisadores empregados.

Todos esses setores que sofreram queda no emprego de pesquisadores, haviam sido citados como pontos importantes de interação por Rapini (2007), Suzigan (2009) e Rapini et al. (2009), em especial, os setores de produtos siderúrgicos, equipamentos de informática, e aqueles ligados às indústrias química e farmacêutica. Dentre os setores que aumentaram $\circ$ emprego de pesquisadores, alguns foram citados pela literatura, tal como a produção de coque e biocombustíveis (álcool e outros) e produção de celulose e papel.

\footnotetext{
5 Para mais detalhes sobre a classificação da OECD, consulte Hatzichronoglou (1997).
} 
Tabela 4: Variação entre os anos de 2014 e 2017, no número de pesquisadores com ensino superior empregados em P\&D, para os 14 setores que mais cooperaram com universidades, e de acordo com o nível tecnológico dos setores.

\begin{tabular}{|c|c|c|}
\hline Setor & $\begin{array}{l}\text { Intensidade } \\
\text { Tecnológica }\end{array}$ & Variação \\
\hline Fabricação de automóveis - camionetas e utilitários - caminhões e ônibus. & Média-alta & -3964 \\
\hline $\begin{array}{l}\text { Fabricação de resinas e elastômeros - fibras artificiais e sintéticas - defensivos } \\
\text { agrícolas e desinfetantes domissanitários. }\end{array}$ & Média-alta & -378 \\
\hline Fabricação de equipamentos de infonmática e periféricos. & Alta & -374 \\
\hline Fabricação de outros produtos eletrônicos e ópticos. & Alta & -179 \\
\hline Produtos siderúrgicos. & Média-baixa & -97 \\
\hline Fabricação de equipamentos de comunicação. & Alta & -66 \\
\hline Fabricação de produtos fammacêuticos. & Alta & -37 \\
\hline $\begin{array}{l}\text { Fabricação de instrumentos e materiais para uso médico e odontológico e de } \\
\text { artigos ópticos. }\end{array}$ & Média-alta & -5 \\
\hline Fabricação de produtos farmoquímicos. & Alta & 9 \\
\hline Fabricação de produtos químicos inorgânicos. & Média-alta & 16 \\
\hline Fabricação de produtos do fumo. & Baixa & 51 \\
\hline Fabricação de coque e biocombustiveis (álcool e outros). & Média-baixa & 56 \\
\hline Fabricação de celulose e outras pastas. & Baixa & 65 \\
\hline $\begin{array}{l}\text { Fabricação de tintas - vernizes - esmaltes - lacas e produtos afins e de produtos } \\
\text { diversos. }\end{array}$ & Média-alta & 551 \\
\hline
\end{tabular}

Fonte: Base de dados da PINTEC-IBGE. Notas: Classificação por intensidade tecnológica da OECD Cavalcante (2014).

Diferentemente do presente trabalho, Rapini (2007) e Suzigan (2009) utilizaram os dados dos Grupos de Pesquisa do CNPq, e Rapini et al. (2009) usaram uma amostra coletada através de uma survey aplicada no estado de Minas Gerais. Porém, mesmo com essa diferença importante, os setores definidos pela PINTEC, como os que possuem uma maior conexão com as universidades, condizem em grande parte com os setores definidos pelos trabalhos citados. Todavia, ainda falta uma presença maior de setores ligados às Ciências Agrárias na PINTEC. Setores estes que têm se mostrado, ao longo de todas essas pesquisas, os principais polos de interações entre as universidades e a indústria no país.

Além dos pesquisadores pós-graduados estarem concentrados na administração pública, eles também não fazem parte da maioria dos pesquisadores empregados nos setores 
produtivos. Pode-se observar na tabela 5 que, se comparado aos demais, os pesquisadores pós-graduados vêm ganhando espaço. Entretanto, essa conquista de terreno está a passos muito lentos.

Tabela 5: Número de pesquisadores empregados em atividades de P\&D interno.

\begin{tabular}{cccccccc}
\hline Variável & $\mathbf{2 0 0 0}$ & $\mathbf{2 0 0 3}$ & $\mathbf{2 0 0 5}$ & $\mathbf{2 0 0 8}$ & $\mathbf{2 0 1 1}$ & $\mathbf{2 0 1 4}$ & $\mathbf{2 0 1 7}$ \\
\hline Pesquisadores graduados & 17.062 & 18.552 & 23.145 & 24.719 & 31.810 & 37.616 & 28.446 \\
& & & & & & & \\
Pesquisadores pós-graduados & 2.910 & 3.068 & 4.280 & 4.340 & 5.632 & 6.214 & 5.668 \\
Pesquisadores com ensino médio & 14.765 & 12.181 & 14.730 & 12.987 & 7.604 & 8.604 & 6.112 \\
\hline
\end{tabular}

Fonte: Base de dados da PINTEC-IBGE. Notas: Números dizem respeito apenas aos setores da indústria de transformação.

Os pesquisadores com pós-graduação possuem conexões mais fortes com a comunidade científica, consequentemente, trazem maiores incentivos para a cooperação entre universidades e indústria. Além disso, tais profissionais possuem maiores estímulos para a pesquisa, sendo este estímulo menor em pesquisadores graduados. Diante disso, pode-se afirmar que há uma problemática frente a um cenário onde grande parte dos pesquisadores empregados nas atividades de P\&D nos setores da indústria de transformação possuem apenas ensino médio completo ou graduação.

\section{CENÁRIO ECONÔMICO: INVESTIMENTO, EXPECTATIVAS E INOVAÇÃO}

\subsection{POLÍTICAS DE CT\&I NO BRASIL}

No geral, a fraca evolução na participação de universidades e institutos de pesquisa indica que as políticas de incentivo à cooperação entre U-I não têm sido muito eficazes. Isso não é novo, pois a literatura confirma a falta nas políticas de CT\&l atuais de uma perspectiva de longo prazo que reconheça o caráter sistêmico da inovação (PACHECO; ALMEIDA, 2013; MAZZUCATO; PENNA, 2016; CASSIOLATO; LASTRES, 2019). Essas políticas ganharam um pouco mais de complexidade durante os governos Lula e Dilma, com algumas melhorias importantes (CASSIOLATO; LASTRES; SOARES, 2014), mas os números mostrados na seção 4 e na próxima seção provam que ainda há muito o que melhorar. 
Além dessa falta, as políticas macroeconômicas implícitas adotadas nos últimos anos, têm representado um obstáculo para a efetividade das políticas de CT\&l existentes. Algumas dessas medidas seriam as altas taxas de juros praticadas na economia, a valorização dos termos de troca e o câmbio apreciado (OREIRO; FEIJÓ, 2010). Tais políticas desincentivam os investimentos produtivos no lado real da economia (CASSIOLATO, 2015), e há evidências de que essas mesmas ações deslocam a demanda por insumos industriais para fora do país, ao invés de baratear os insumos importados de maior conteúdo tecnológico para a indústria nacional (SARTI; HIRATUKA, 2018). Por isso, uma maior sincronia entre as políticas macroeconômicas e as políticas de CT\&l adotadas pelo governo é necessária (MAZZUCATO; PENNA, 2016).

Atualmente, o fomento da inovação no Brasil se dá principalmente por fontes de financiamento 6 (tanto de recursos reembolsáveis quanto não reembolsáveis) e por políticas de incentivo fiscal7 (NEGRI; KUBOTA, 2008). No caso da cooperação entre U-I, a Lei da Inovação (Lei 10.973/2004) foi muito importante por criar avanços legais que facilitaram essa relação. Um exemplo desses avanços, é a possibilidade das universidades emprestarem seus laboratórios e insumos por meio de simples contratos, além de seus pesquisadores poderem se afastar temporariamente de seus cargos para trabalharem em projetos na indústria.

Para mais, tem-se estruturas formadas especificamente para $\circ$ financiamento de projetos de P\&D cooperativos entre firmas e instituições de pesquisa e, programas de subvenção econômica para pesquisadores, em que o governo concede recursos diretamente à empresa, para ajudar no pagamento de salários dos pesquisadores - pesquisadores esses que podem ser provenientes de outras instituições de ensino e pesquisa.

Vale destacar, que apesar dos resultados fracos, as políticas trazidas pela Lei de Inovação foram muito bem recebidas e elogiadas (NEGRI; KUBOTA, 2008; CASSIOLATO; LASTRES; SOARES, 2014). Ou seja, não há uma discussão para retirar essas reformas, mas, sim, para intensificá-las no país (PACHECO; ALMEIDA, 2013) e, principalmente, diversificá-las (MAZZUCATO; PENNA, 2016). Muitas das políticas de CT\&I no Brasil se concentram no lado da oferta. Portanto, seu papel é reduzir custos e prover incentivos, tanto para as instituições que dão suporte tecnológico e científico quanto para as firmas investirem em atividades inovativas.

\footnotetext{
- O Banco Nacional do Desenvolvimento (BNDES) e a Financiadora de Estudos e Projetos (FINEP), ligada ao Ministério da Ciência e da Tecnologia, são as duas principais instituições envolvidas na administração e no financiamento de recursos. Há também programas e recursos oferecidos pelas Fundações Estaduais de Amparo à Pesquisa e pelo Conselho Nacional de Desenvolvimento Científico e Tecnológico (CNPq).

7 Lei do Bem - Lei $11.196 / 2005$ e Lei da Informática - Lei 8.248/1991.
} 
Faria

Essas políticas, automaticamente, pressupõem a existência de uma demanda, não só pelo suporte oferecido pelas instituições, mas também pelas atividades inovativas por parte das firmas.

No entanto, essa demanda está muito fraca (MAZZUCATO; PENNA, 2016; RAPINI, 2018). A evolução dos números apresentados até o momento e os números mostrados na seção abaixo indicam um agravamento desse cenário. Por isso, a entrada de mais políticas de CT\&l no país, pelo lado da demanda ${ }^{8}$, seria um passo importante .

Uma das proposições de Rapini (2018) é que as políticas de CT\&I deveriam incluir projetos e empresas em níveis mais elevados de incertezas. Nesse sentido, o governo deveria ser não apenas o financiador, mas também quem cria os mercados para as firmas nos níveis mais altos de incerteza. Ou seja, o governo organizaria e financiaria um grupo de instituições, na pesquisa e desenvolvimento de um produto que seria de interesse público, focando na resolução de problemas atuais que afetam a sociedade.

A crise atual da COVID-19, por exemplo, tem mostrado a importância do fortalecimento da indústria farmacêutica brasileira. Esse exemplo é marcante para um país que possui organizações muito importantes nas áreas da saúde, tais como a Fundação Oswaldo Cruz, - Instituto Butantã e a Fundação Ezequiel Dias, que são capazes de contribuir muito para tal desenvolvimento e produção. Logo, o governo poderia organizar e financiar essas instituições em conjunto com a indústria farmacêutica do país, para a produção específica dos produtos que são de interesse de toda a população brasileira.

\subsection{INVESTIMENTO E REFLEXOS SOBRE AS ATIVIDADES INOVATIVAS}

Os números de 2017 apresentam um claro retrocesso da inovação no Brasil. Pela primeira vez, todos os principais indicadores de inovação registraram queda. $O$ que argumentase é que grande parte desse recuo é explicada pela drástica queda do investimento produtivo no país (NEGRI et al., 2020).

O produto manufatureiro (PIB da indústria) encontrava-se em um leve declínio desde 2011 (SARTI; HIRATUKA, 2018), e a taxa de investimento (taxa de formação bruta de capital fixo), que se recuperou rapidamente após a crise de 2008, entrou em estagnação em 2012. Entretanto, posteriormente ao último trimestre de 2013, ambas as variáveis entraram em forte

8 Para teoria e exemplos de prática, veja Edler e Georghiou (2007) e Lember et al. (2014).

24 Revista Multiface / Belo Horizonte / v. 9, n. 1, p. 5-36, 2021 
enfraquecimento. A queda no investimento em específico ${ }^{9}$ é explicada, em grande medida, pelo arrefecimento do consumo das famílias (CARNEIRO, 2017) e pelos erros monetários e cambiais do governo (CARNEIRO, 2017; ARESTI et al., 2019). Mais à frente, as políticas (pró-cíclicas) de austeridade fiscal do governo e a queda nos investimentos públicos também vão contribuir para esse enfraquecimento (SARTI; HIRATUKA, 2018; ARESTI et al., 2019).

Em comparação ao ano de 2014 , a taxa de inovação geral caiu de $36 \%$ para $33,6 \%$. A proporção dos gastos em atividades inovativas, em relação à receita líquida total caiu de $2,54 \%$ para $1,95 \%$, sendo que o pior impacto recaiu sobre a indústria (a qual teve uma queda, nesse índice, pela terceira edição consecutiva) e sobre os serviços selecionados (PINTEC, 2020). A participação dos gastos especificamente em $P \& D$ interno, externo e aquisição de máquinas e equipamentos em relação à receita líquida total, caiu de $0,77 \%$ para $0,74 \%$; de $0,28 \%$ para $0,2 \%$; e de $1,04 \%$ para $0,62 \%$, respectivamente.

Em valores reais ${ }^{10}$ de 2017 , os gastos em aquisições de máquinas e equipamentos sofreram uma queda drástica (de 48,1\% em relação a 2014), acima da queda do total de gastos em atividades inovativas (de 32,3\% em relação a 2014). Enquanto isso, os gastos nominais em P\&D interno aumentaram em 3,73\%, contudo, em valores reais, esses gastos caíram $15 \%$. Por isso, a aquisição de máquinas e equipamentos perdeu de forma considerável a sua participação no total de gastos em atividades inovativas (33,72\% em 2017), enquanto o P\&D interno passou a ser a principal atividade inovativa em termos de volume de gastos $(37,99 \%$ em 2017).

Com isso, especula-se que o P\&D ganhou maior relevância para as firmas inovadoras, como mostrou a tabela 1, mas isso não significa que ele ganhou importância na economia como um todo, pois a participação dos gastos totais em P\&D sobre o PIB da economia caiu (NEGRI et al., 2020, Tabela 1). Como visto nos parágrafos anteriores, todas as atividades inovativas perderam participação em relação à receita líquida total. Ou seja, mesmo com o aumento dos gastos nominais em P\&D, as firmas estão investindo proporcionalmente menos nessas atividades comparado a 2014.

A queda em todos os principais indicadores de inovação indica um declínio na demanda das empresas por atividades inovativas que ocorre em resposta à diminuição do investimento

\footnotetext{
9 Os fatores citados acima também contribuíram para a queda no PIB industrial, entretanto, como esse entrou em queda antes que os fatores surgissem, outros pontos devem ser considerados. Sarti e Hiratuka (2018) fornecem um desses pontos que podem explicar essa queda "antecipada".

10 Foi utilizado o índice acumulado do IPCA de dezembro de 2014 a dezembro de 2017, para trazer os valores de 2014 para 2017.
} 
produtivo no país. $O$ incentivo, especificamente do investimento produtivo, pode tornar-se um ponto importante nessa discussão não apenas pelos efeitos negativos sobre a demanda por atividades inovativas, mas também pelos efeitos do avanço da financeirização na economia brasileira. Isso, pois, como Bresser-Pereira, Paula e Bruno (2020, p. 8) argumentam, estudos já comprovaram que a financeirização limita muito o impacto das políticas públicas (como as políticas de CT\&l) no comportamento das empresas.

\subsection{UM ESTADO MENOR}

Outro ponto, além do investimento, que explica a queda do P\&D e da aquisição de máquinas e equipamentos, é a redução do suporte público às atividades inovativas (NEGRI et al., 2020). Há evidências disso em: 1) o percentual de empresas que receberam algum tipo de suporte do governo caiu de $39,9 \%$ para $26,2 \% ; 2$ ) a distribuição das fontes de financiamento tanto do P\&D interno quanto das demais atividades (Tabela 8 da PINTEC) mostra que a participação pública caiu, consideravelmente, em quase todos os setores. No caso do P\&D interno, a participação total pública (como fonte de financiamento) caiu de 14,29\% para 7,44\% e nas demais atividades, de $12 \%$ a $6 \%$; 3 ) o número de empresas que receberam financiamento do governo para a compra máquinas e equipamentos caiu em mais de 50\%, de 14240 para 5026 .

A redução do Estado no apoio à inovação é preocupante. Pelo fato de a inovação envolver, por definição, grandes incertezas, as instituições de mercado tendem a alocar de forma ineficiente os recursos para essa atividade (NELSON, 1959; ARROW, 1962). Uma firma que segue a lógica maximizadora de lucro decide, ou não, investir em um projeto de acordo com a relação entre o custo e o retorno esperado do investimento. No entanto, não há como estimar, de forma precisa, os custos ou o tempo necessários para o desenvolvimento do projeto, muito menos o retorno real de um investimento como a inovação (FREEMAN; SOETE, 2008). Isso, pois, a incerteza existente no processo é knightiana ${ }^{11}$ e, portanto, não é possível que seja calculada por meio de probabilidades (MAZZUCATO, 2013).

O processo inovativo é de longo prazo e por isso exige recursos que sejam pacientes - suficiente para permanecerem disponíveis durante o período (MAZZUCATO, 2014), e as evidências mostram que o mercado financeiro e bancário privado não tem sido paciente $\circ$

\footnotetext{
11 Esse conceito refere-se à definição de incerteza dada pelo economista Frank H. Knight, em seu livro "Risco, Incerteza e Lucro" ("Risk, Uncertainty and Profit"), publicado em 1921.
} 
suficiente (MAZZUCATO, 2013). Isso não significa que não haja P\&D ou outras atividades inovativas que sejam financiadas por recursos privados ou próprios da empresa. Mas, como foi pontuado por Pavitt (1991), os investimentos privados e públicos nessas atividades são complementares. Sendo assim, por tudo que foi exposto acima, sem alguma presença pública, pouco resta para ser investido.

Esses efeitos serão mais perversos sobre a estrutura científica do país, que geralmente precisa de uma parcela pública maior de recursos, por dois motivos. Primeiro, as universidades e institutos de pesquisa realizam mais frequentemente pesquisas básicas. Ou seja, essas instituições produzem, em sua maioria, um conhecimento que é geral, ou, em outras palavras, que não é específico o suficiente para ser aplicado diretamente à produção (PAVITT, 1991). Segundo, justamente por ser uma pesquisa básica, ela acumula todos os tipos de incertezas envolvidas no processo de inovação (FREEMAN; SOETE, 2008), incertezas que geralmente não são encontradas em outros estágios do processo. Por conta disso, menos capital privado tende a ir para essas atividades.

Menos recursos para as universidades públicas significa que menos projetos de pesquisa serão financiados e menos bolsas de pesquisa serão ofertadas pelas instituições de pesquisa. Isso tem um grande impacto, pois uma forte base científica fornece importantes ferramentas que permitem ao processo de desenho e invenção ser mais produtivo e potente do que seria caso essa base fosse frágil (NELSON, 2006), e, mais especificamente, no caso de países emergentes como o Brasil, significa que menos demandas da sociedade poderão ser desenvolvidas e atendidas pelas instituições.

\section{CONCLUSÃO}

Os dados da PINTEC indicam que as políticas de CT\&I atuais tiveram pouco efeito (apesar de positivo) sobre a aproximação entre a ciência brasileira e a indústria. Em outras palavras, os resultados indicam que as universidades e os institutos de pesquisa não participaram de maneira expressiva no desenvolvimento tecnológico mais recente do país, com algumas pouquíssimas exceções ${ }^{12}$.

\footnotetext{
12 Algumas dessas exceções seriam a ligação entre a Embraer e o Instituto Tecnológico da Aeronáutica (ITA), as relações da Petrobras com algumas universidades, $\circ$ papel fundamental da Embrapa na competitividade da agropecuária brasileira, além da Fundação Oswaldo Cruz (Fiocruz) no campo da saúde (MAZZUCATO; PENNA, 2016; CASSIOLATO; LASTRES, 2019).
} 
A proporção de firmas que cooperaram com universidades e institutos de pesquisa sobre o total de firmas que inovaram era de 1,5\% em 2000 e chegou a 2,65\% em 2017 . Isso representa um avanço pouco expressivo, que não foi capaz de alterar a rede de interações das empresas. Ao olharmos para as fontes de informações de alta importância para a inovação das firmas, as universidades e os institutos de pesquisa permanecem nos últimos lugares durante todo - período, entre $2 \%$ e $3 \%$ das respostas. Logo, o cenário enunciado pela literatura, no qual menos de $3 \%$ das firmas inovadoras cooperam com universidades (CASSIOLATO; LASTRES, 2019), permaneceu intacto.

Tal situação do país pode ser explicada, como argumentado por Rapini (2018), por uma "fragmentação do processo de aprendizado", no sentido dado por Arocena e Sutz (2010). Buscou-se argumentar, de forma complementar à análise de Rapini (2018), que além das proposições feitas pela autora, parte da solução desse sintoma também incluiria: 1) para além de uma distribuição mais homogênea dos estudantes entre as áreas da ciência no ensino superior, uma expansão no acesso da população às universidades, para que um número maior de pessoas possa contribuir com o desenvolvimento tecnológico a longo prazo do país; 2) diversificação das políticas de CT\&l, em especial, a implementação de mais políticas pelo lado da demanda; 3) a necessidade de alavancar o investimento produtivo na economia.

Os indicadores de inovação em 2017 apresentaram uma piora das condições de inovação das firmas. Essa fragilização pode ser explicada pela drástica queda do investimento produtivo (taxa de formação bruta de capital fixo), que se iniciou entre o último trimestre de 2013 e o primeiro trimestre de 2014, sendo posteriormente agravada pelas políticas (prócíclicas) de austeridade fiscal adotadas pelo governo, as quais não conseguiram reverter as expectativas pessimistas dos empresários (SARTI; HIRATUKA, 2018; ARESTI et al., 2019). Outras políticas macroeconômicas implícitas adotadas nos últimos anos também afetaram negativamente as políticas industriais e de inovação do país (MAZZUCATO; PENNA, 2016). Algumas dessas políticas seriam as altas taxas de juros praticadas na economia, a valorização dos termos de troca e o câmbio apreciado (OREIRO; FEIJÓ, 2010; CASSIOLATO, 2015). Tais políticas desincentivaram os investimentos produtivos no lado real da economia (CASSIOLATO, 2015) e, ao invés de baratear os insumos importados de alto teor tecnológico para a indústria, há evidências de que elas deslocaram a demanda por insumos industriais para fora do país (SARTI; HIRATUKA, 2018).

Rapini (2018) argumenta que as empresas precisam alavancar suas capacidades de absorção, por meio de uma maior contratação de pesquisadores pós-graduados e/ou maiores 
investimentos em P\&D interno. Contudo, em 2017, as empresas passaram a empregar um número menor de pesquisadores (em todos os níveis de escolaridade) e a investir proporcionalmente menos em todas as atividades inovativas. $O$ baixo crescimento nos gastos em P\&D interno em 2017 de 3,73\% em relação a 2014 (sendo que esse número em 2014 foi de 23,79\% comparado a 2011 ) indica uma forte queda na demanda pelas atividades inovativas.

Por isso, além de fornecer mais mecanismos de suporte à contratação de pesquisadores pelas empresas, é necessário uma diversificação das políticas de CT\&I (incluir políticas tanto relacionadas à oferta quanto à demanda), de integrar melhor as políticas macroeconômicas e possuir uma visão a longo prazo (PACHECO; ALMEIDA, 2013; MAZZUCATO; PENNA, 2016; CASSIOLATO; LASTRES, 2019). A ausência desses fatores e o cenário macroeconômico desfavorável aumentaram os custos e as incertezas sobre o processo inovativo. Como resultado, a demanda das firmas por atividades inovativas em geral caiu. Portanto, no cenário atual, as firmas têm escolhido manter a competitividade por meio da redução de custos e da absorção de tecnologias já existentes no mercado, ao invés da inovação (CASSIOLATO, 2015).

\section{REFERÊNCIAS}

ALBUQUERQUE, E.; SUZIGAN, W.; KRUSS. G.; LEE, K. Developing National Systems of Innovation: university - industry interactions in the global south. Cheltenham: Edward Elgar Publishing. 2015.

ALDERMAN, H. No Small Matter: The Impact of Poverty, Shocks, and Human Capital Investments in Early Childhood Development. Washington, D.C.: The World Bank, 2011.

ARESTIS, P.; FILHO, F.; RESENDE, M.; TERRA, F. Brazilian Monetary and Fiscal Policies from 2011 to 2017: Conventions and Crisis. Challenge, v. 62, n. 3, 2019. p. 187-199.

AROCENA, R.; SUTZ, J. Weak knowledge demand in the South: learning divides and innovation policy. Science and Public Policy, v. 37, n. 8, 2010. p. 571-582.

ARROW, K. Economic Welfare and the Allocation of Resources for Invention. In: NELSON, R. The Rate and Direction of Inventive Activity. Princeton University Press. 1962. p. 609-626.

BRESSER-PEREIRA, L. C.; PAULA, L. F.; BRUNO, M. Financialization, coalition of interests and interest rate in Brazil. Revue de la régulation, v. 27, abr. de 2020. 
Faria

BRITTO, G.; SANTOS, U.; KRUSS, G.; ALBUQUERQUE, E. Global interactions between firms and universities. Innovation and Development, v. 3, 2013. p. 571-582.

BRUNEEL, J.; D'ESTE, P.; SALTER, A. Investigating the factors that diminish the barriers to universityindustry collaboration. Research Policy, v. 39, 2010. p. 858-868.

BRUNS, B.; EVANS, D.; LUQUE, J. Achieving World-Class Education in Brazil: The Next Agenda. Washington, D.C.: The World Bank, 2012.

CARNEIRO, R. Navegando a contravento: Uma reflexão sobre o experimento desenvolvimentista do Governo Dilma Rousseff. Texto para Discussão, Campinas, IE/UNICAMP, n. 289, 2017.

CASSIOLATO, J.; LASTRES, H.; SOARES, M. The Brazilian national system of innovation: Challenges to sustainability and inclusive development. In: DUTRÉNIT, G.; SUTZ, J. National Innovation Systems, Social Inclusion and Development: the Latin American Experience. 1ed., Cheltenham: Edward Elgar Publishing, 2014. p. 68-101.

CASSIOLATO, J. Evolution and Dynamics of the Brazilian National Innovation System. In: SHOME, P.; SHARMA, P. Emerging Economies: Food and Energy Security, and Technology and Innovation. New York: Springer, 2015. p. 265-310.

CASSIOLATO, J. et al. O Papel das Universidades e Instituições Públicas de Ensino e Pesquisa no Desenvolvimento Territorial Sustentável: uma breve nota introdutória. Texto para Discussão, n. 1, Rio de Janeiro, RedeSist, 2018.

CASSIOLATO, J.; LASTRES, H. The Brazilian National System of Innovation: its evolution and dynamics at the end of the second decade of the millenium. Texto para Discussão, n. 4, Rio de Janeiro, RedeSist, 2019.

CAStro, J. A. Evolução e desigualdade na educação brasileira. Educação e Sociedade. Campinas, v. 30 , n. 108, out. 2009, p. 673-697.

CAVALCANTE, L. Classificações tecnológicas: uma sistematização. Nota Técnica - IPEA, n. 17, Brasília, mar. de 2014 Disponível em: <https://www.ipea.gov.br/portal/index.php?option=com content\&view=article\&id=21829>. Acesso em: 30 nov. 2020. 
CGGE [Centro de Gestão e Estudos Estratégicos]. Mestres e doutores 2015: Estudos da demografia da base técnico-científica brasileira. Brasília: Centro de Gestão e Estudos Estratégicos, 2015.

COHEN, W.; NELSON, R.; WALSH, J. Links and Impacts: The Influence of Public Research on Industrial R\&D. Management Science, v. 48, n. 1, 2002. p. 1-23.

EDLER, J.; GEORGHIOU, L. Public procurement and innovation-resurrecting the demand side. Research Policy, v. 36, 2007. p. 949-963.

FREEMAN, C.; SOETE, L. A Economia da Inovação Industrial. Campinas, SP: Editora Unicamp, 2008.

FREITAS, I.; MARQUES, R.; SILVA, E. University - industry collaboration and innovation in emergent and mature industries in new industrialized countries. Research Policy, v. 42, 2013. p. 443-453.

GARCIA, R.; RAPINI, M.; CÁRIO, S. Estudos de caso da interação universidade-empresa no Brasil. Belo Horizonte: FACE/UFMG, 2018.

HATZICHRONOGLOU, Thomas. Revision of the high-technology sector and product classification. OECD Science, Technology and Industry Working Papers, Paris, n. 2, 1997.

HIRATUKA, C.; SARTI, F. Transformações na estrutura produtiva global, desindustrialização e desenvolvimento industrial no Brasil: uma contribuição ao debate. Texto para Discussão, IE/UNICAMP, Campinas, n. 255, 2015.

HORVAT, D.; DREHER, C.; SOM, O. How firms absorb external knowledge: modelling and managing the absorptive capacity process. International Journal of Innovation Management, v. 23, n. $1,2019$.

IBGE [Instituto Brasileiro de Geografia e Estatística]. Síntese de Indicadores Sociais: uma análise das condições de vida da população brasileira. Rio de Janeiro, Edição 2014.

IBGE [Instituto Brasileiro de Geografia e Estatística]. Síntese de Indicadores Sociais: uma análise das condições de vida da população brasileira. Rio de Janeiro, Edição 2019. 
Faria

IPEA [Instituto de Pesquisa Econômica Aplicada]. Carta de Conjuntura - Mercado de trabalho. Brasília, n. $32,3^{\circ}$ trimestre de 2016.

IPEA [Instituto de Pesquisa Econômica Aplicada]. Carta de Conjuntura - Mercado de trabalho. Brasília, n. $46,1^{\circ}$ trimestre de 2020.

INEP [Instituto Nacional de Estudos e Pesquisas Educacionais Anísio Teixeira]. Estimativas de fluxo escolar a partir do acompanhamento longitudinal dos registros de aluno do Censo Escolar do período 2007-2016. Nota técnica, № 8/2017/CGCQTI/DEED, Brasília, junho de 2017. Disponível em: <http://download.inep.gov.br/informacoes estatisticas/indicadores educacionais/2007 201 6/nota tecnica taxas transicao 2007 2016.pdf >. Acesso em: 30 de nov. 2020.

LALL, S. A Mudança Tecnológica e a Industrialização nas Economias de Industrialização Recente da Ásia: conquistas e desafios. In: KIM, L.; NELSON, R. Tecnologia, aprendizado e inovação: as experiências das economias de industrialização recente. Campinas, SP: Editora Unicamp, 2005. p. 25-100.

LALL, S. Technological Capabilities and Industrialization. World Development, v. 20, n. 2, 1992. p. $165-186$.

LANGLOIS, R. Economic Institutions and the Boundaries of the Firm: The Case of Business Groups. University of Connecticut: Working Paper, 2009.

LEMBER,V.; KATTEL, R.; KALVET, T.. Public Procurement, Innovation and Policy. New York: Springer, 2014.

LUNDVALL, B.-A. Knowledge Management in the Learning Economy. Danish Research Unit for Industrial Dynamics (DRUID): Working Paper, n. 06-6, 2006.

LUNDVALL, B.-A. National Systems of Innovation: Towards a Theory of Innovation and Interactive Learning. New York: Anthem Press, 2010.

MAZZUCATO, M. Financing innovation: creative destruction vs. destructive creation. Industrial and Corporate Change, v. 22, n. 4, 2013. p. 851-867. 
MAZZUCATO, M. O Estado Empreendedor: desmascarando o mito do setor público vs. setor privado. São Paulo: Portfolio Penguin, 2014.

MAZZUCATO, M.; PENNA, C. The Brazilian Innovation System: A Mission-Oriented Policy Proposal. Brasília: Centro de Gestão e Estudos Estratégicos - CGGE, 2016.

MORAES, C.; OLIVEIRA, A.; REICHENHEIM. M.; GAMA, S.; LEAL, M. et al. Prevalência de violência física entre parceiros íntimos nos primeiros seis meses após o parto no Município do Rio de Janeiro. Cadernos de Saúde Pública, v. 33, n. 8, 2017.

MURRAY, F. The role of academic inventors in entrepreneurial firms: sharing the laboratory life. Research Policy, v. 33, 2004. p. 643-659.

NEGRI, F. Redução drástica na inovação e no investimento em $P \& D$ no brasil: o que dizem os indicadores da pesquisa de inovação 2017. Nota Técnica - IPEA, n. 60, abr. de 2020. Disponível em:

$<$ https://www.ipea.gov.br/portal/index.php?option=com content\&view=article\&id $=35477 \&$ l temid=8>. Acesso em: 30 nov. 2020.

NEGRI, J.; KUBOTA, L. Políticas de Incentivo à Inovação Tecnológica no Brasil. Brasília -IPEA, 2008.

NELSON, R. The Simple Economics of Basic Scientific Research. Journal of Political Economy, v. 67, 1959. p. 297-306.

NELSON, R. Reflections on "The Simple Economics of Basic Scientific Research": looking back and looking forward. Industrial and Corporate Change, v. 15, 2006. p. 903-917.

OREIRO, J.; FEIJÓ, C. Desindustrialização: conceituação, causas, efeitos e o caso brasileiro. Revista de Economia Política, v. 30, n. 2, 2010. p. 219-232.

PACHECO, C.; ALMEIDA, J. A política de inovação. Texto para Discussão, Campinas: IE/UNICAMP, n. 219, 2013.

PARANHOS, J.; HASENCLEVER, L. Teoria da firma e empresa inovadora. In: RAPINI, M.; SILVA, L.; ALBUQUERQUER, E. Economia da ciência, tecnologia e inovação: fundamentos teóricos e a economia global. $1^{a}$ ed., Curitiba: Editora Prismas, 2017. p. 99-130. 
Faria

PAVITT, K. What makes basic research economically useful?. Research Policy, vol. 20, n. 6, 1991. p. 109-119.

PEREZ, C. Technological revolutions and technoeconomic paradigms. Cambridge Journal of Economics, v. 34, 2010. p. 185-202.

PINTEC [Pesquisa de Inovação]. Informativo da PINTEC 2017. Rio de Janeiro: IBGE, Diretoria de Pesquisas, 2020.

RAPINI, M.; ALBUQUERQUE, E.; CHAVE, C.; SILVA, L.; SOUZA, S.; RIGHI, H.; CRUZ, W. Universityindustry interactions in an immature system of innovation: evidence from Minas Gerais, Brazil. Science and Public Policy, v. 36, 2009. p. 373-386.

RAPINI, M. Interação Universidade-Empresa no Brasil: Evidências do Diretório dos Grupos de Pesquisa do CNPq. Estudos Econômicos, v. 37, n. 1, 2007. p. 221-233.

RAPINI, M.; CHIARINI, T.; BITTENCOURT, P. Obstacles to Innovation in Brazil: Lack of Qualified Personnel to Implement Innovation and to Establish University - Firm Interactions. Industry and Higher Education, v. 31, n. 3, 2017.

RAPINI, M. Cooperação universidade-empresa: realidade e desafios. In: ANDRADE, M. V.; ALBUQUERQUE, E. Alternativas para uma crise de múltiplas dimensões. Belo Horizonte: FACE/UFMG, 2018. p. 375-390.

REICHENHEIM, M.; SOUZA, E.; MORAES, C.; JORGE, M.; SILVA, C.; MINAYO, M. Violence and injuries in Brazil: the effect, progress made, and challenges ahead. The Lancet, v. 377, n. 9781, 2011.

SARTI, F.; HIRATUKA, C. Desempenho recente da indústria brasileira no contexto de mudanças estruturais domésticas e globais. In: CARNEIRO, R.; BALTAR, P.; SARTI, F.; Para Além da Política Econômica. São Paulo: Editora Unesp Digital, 2018. p. 127-170.

SILVA, D.; FURTADO, A.; VONORTAS, N. University-industry R\&D cooperation in Brazil: a sectoral approach. The Journal of Technology Transfer, v. 43, 2018. p. 285-315.

SUZIGAN, W.; ALBUQUERQUE, E.; GARCIA, R.; RAPINI, M.University and Industry Linkages in Brazil: Some Preliminar and Descriptive Results. Seoul Journal of Economics, v. 22, n. 4, 2009. 
Cooperação Universidade - Indústria no Brasil

VON HIPPEL, E. The Sources of Innovation. New York: Oxford University Press, 1988. 
Faria

Artigo submetido em junho de 2020 e aprovado em janeiro de 2021.

36 Revista Multiface / Belo Horizonte / v. 9, n. 1, p. 5-36, 2021 